\title{
Nuevos espacios para la cultura. Estrategias, equipamientos e impacto en la ciudad postindustrial y portuaria de Gijón
}

\author{
New spaces for Culture. Strategies, equipment and impact in \\ the postindustrial and port city of Gijón

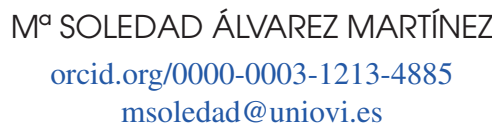 \\ CARMEN BERMEJO LORENZO \\ orcid.org/0000-0001-5675-212X \\ berloren@uniovi.es \\ JUAN SEVILLA ÁLVAREZ \\ Universidad de Oviedo \\ orcid.org/0000-0001-6235-0020 \\ sevillajuan@uniovi.es
}

\section{RESUMEN}

Gijón constituye un ejemplo pionero de recurso a la cultura como motor de cambio y un modelo en cuanto al protagonismo otorgado a los equipamientos culturales dentro de los planes estratégicos proyectados para regenerar la trama urbana en todos sus sectores tras la crisis industrial. El diseño y mantenimiento de una política cultural socializadora y de gran calado a lo largo de tres décadas (1979-2011) ha sido posible por la estabilidad política municipal, en sintonía con el Gobierno del Principado, demostrando un claro empeño en impulsar la revitalización de una de las ciudades asturianas más castigadas por la reconversión económica ${ }^{1}$.

Palabras clave: Equipamientos culturales, regeneración urbana, espacios portuarios, escultura pública, Gijón.

1 Este trabajo forma parte del proyecto de I+D+i Focos de creación, impulso e innovación: equipamientos para nuevos entornos urbanos en el litoral cantábrico (HAR2015-64219-P) que ha sido financiado por el Ministerio de Economia y Competitividad dentro del Programa Estatal de Fomento de la Investigación Científica y Técnica de Excelencia. 


\begin{abstract}
Gijón is a pioneer example on how culture could drive a change, as well as role as a model, in terms of cultural facilities. Furthermore, the aforementioned situation is also contextualized after the industrial crisis and besides the strategic plans which were designed to regenerate the urban fabric. The design and maintenance of a socializing cultural policy over three decades (1979-2011) has been possible because of the municipal political stability, in tune with the Government of the Principality of Asturias. Moreover, these politics were focused on demonstrating a commitment to promote the revitalization of one of the most punished Asturian cities because of the economic reconversion.
\end{abstract}

Keywords: Cultural facilities, urban regeneration, port spaces, public sculpture, Gijón.

En 2011, en plena crisis económica mundial, el sociólogo y filósofo polaco Zygmunt Bauman (1925-2017), en el acto inaugural del Congreso Europeo de Cultura celebrado en Wroclaw (Polonia), se refería a la cultura como principal fuente de recursos económicos de Europa (Martí Font: 2011). Ese planteamiento economicista no era nuevo (Bauman, 2013). Había comenzado a emplearse en el ámbito europeo occidental en las décadas finales del siglo XX y en España se hacía especialmente notorio en los años noventa (Álamo Núñez, 2014) vinculado a los planes estratégicos de regeneración puestos en marcha con el objetivo de paliar los efectos de la reconversión industrial.

Desde entonces, los equipamientos culturales, además de desempeñar su función específica, fueron planificados desde la perspectiva de la economía del turismo para potenciar el valor del territorio y aportarle nuevos sentidos y valores que deberían contribuir a su revitalización. Así, la cultura pasó a convertirse en un recurso destacado dentro de las estrategias diseñadas por las administraciones públicas para impulsar la recuperación de ciudades y regiones especialmente castigadas por las transformaciones del sistema productivo y la deslocalización industrial.

Dentro de España, esta situación se hizo especialmente notoria en el Principado de Asturias, uno de los territorios regionales con más establecimientos extractivos e industriales de titularidad estatal que en las últimas décadas del siglo XX asistían a un progresivo desmantelamiento. Las comarcas mineras del Nalón y del Caudal y las ciudades portuarias e industriales de Gijón y Avilés constituyen los más claros exponentes de espacios afectados por dicha situación.

En nuestro contexto regional, el origen de la subordinación de las políticas culturales a las estrategias impulsadas con fines regeneradores debe situarse en Gijón en los últimos años de la década de los ochenta, estableciéndose entonces una alianza entre los gobiernos municipal y autonómico que se hizo especialmente notoria en los noventa y primeros años del siglo XXI hasta la crisis financiera de 2008. Una alianza que, como se desarrollará a continuación, ha tenido consecuencias determinantes en la transformación urbanística, social, económica y cultural del conjunto de la ciudad. 


\section{GIJÓN: RECONVERSIÓN INDUSTRIAL Y DEMOCRATIZACIÓN CULTURAL}

En 1980, después de un siglo de funcionamiento, cerraba la Fábrica de Moreda y Gijón, la primera siderúrgica de la ciudad. Este hecho marca un hito y puede tomarse como símbolo de la situación de la crisis industrial generalizada que sufría la ciudad, que se venía fraguando desde años atrás y que en los años setenta había originado la paulatina desaparición de las diferentes empresas de construcción naval y de producción de acero, además de otras auxiliares relacionadas con ellas. La incidencia de esta situación se acusaba en toda la ciudad y a todos los niveles, pero se hacía especialmente notoria en el sector costero occidental y en sus inmediaciones, donde se localizaban los astilleros y gran parte de las factorías (Alvargonzález Rodríguez, 1985), además de los barrios obreros del oeste y del sur. En esa zona, al problema generado urbanísticamente por el desarrollismo de los años sesenta y comienzos de los setenta, que había dado origen a unos barrios de crecimiento descontrolado y construcción deficiente, se sumaba entonces la necesidad de suturar las cicatrices generadas por las enormes superficies liberadas por las industrias (Sendín, 1990; Fernández, 1991), de recuperar para la ciudad esos terrenos y dotarlos de nuevos usos. Y el problema comenzaría a abordarse a partir de la redacción de un nuevo Plan General de Ordenación Urbana (Plan Rañada), que fue aprobado en diciembre de 1985 y entraba en vigor al año siguiente. Un plan que, para dotar a Gijón de un planeamiento coherente, planteaba como medidas fundamentales: poner freno al crecimiento descontrolado, cohesionar la estructura interna de la trama urbana y mejorar las condiciones de habitabilidad en toda la ciudad. Y la aplicación de ese plan, que con la llegada de Fondos Europeos de Desarrollo Regional (FEDER) se desarrolló por sectores en los correspondientes Planes Especiales de Reforma Interior, tuvo consecuencias determinantes en la transformación de la ciudad a todos los niveles: urbanístico, social, económico y cultural.

Las intervenciones se iniciaron en una de las zonas más afectadas por las transformaciones funcionales: el tómbolo de Cimadevilla, origen de la ciudad de Gijón y desde el siglo XIX enclave que divide los sectores portuario e industrial del oeste y terciario y balneario del este. Un sector que había asistido a la paulatina desaparición de las funciones tradicionales de su puerto histórico (pesca y exportaciones de carbón y minerales) al ser asumidas por el gran puerto industrial de El Musel, en funcionamiento desde 1907, y que albergaba un degradado barrio de pescadores y cigarreras y un terreno de uso militar, propiedad del Ministerio de Defensa, que permanecía prácticamente segregado de la ciudad; con todo, un sector que había sido declarado BIC en 1975 y que, a pesar de la situación de deterioro, tenía un peso simbólico en el colectivo ciudadano.

La regeneración de Cimadevilla (Pol y Martín, 1989) se llevó a cabo a partir de la aplicación de tres intervenciones especiales, ya contempladas en 1982 en el Avance del PGOU, que se ocuparon, respectivamente, de la arquitectura y los viales con el objetivo de mejorar la habitabilidad y la sociabilidad del barrio (Plan Especial de Protección y 
Reforma Interior de Cimadevilla), del Cerro de Santa Catalina con el propósito de integrar en el espacio público los antiguos terrenos militares, y del antiguo puerto, al que se pretendía dotar de nuevas funciones deportivas y culturales. Todas esas intervenciones, llevaron asociados equipamientos culturales de nueva creación dedicados a la puesta en valor y conservación del patrimonio existente en el lugar.

\section{Las intervenciones patrimoniales en Cimadevilla}

En efecto, en Cimadevilla llama la atención el peso que se ha concedido a la cultura en la regeneración del barrio (Álvarez, 2016) incluso antes de que se iniciase en 1989 la intervención urbanística, en unos momentos, a comienzos de los ochenta, en los que desde el Ministerio de Cultura del primer gobierno socialista se promovía la democratización cultural como "instrumento fundamental del cambio" (Rubio, 2003: 111). Las primeras intervenciones de Gijón también se adelantaron a las nuevas políticas culturales del PSOE, pues en 1981 se puso en marcha el Proyecto Gijón de Excavaciones Arqueológicas (1981-1997) coincidiendo con los primeros pactos firmados durante el gobierno de Leopoldo Calvo Sotelo, en la fase previa al traspaso de competencias a las autonomías. El proyecto surgía impulsado por el arqueólogo gijonés Manuel Fernández Miranda, Subdirector General de Arqueología, cargo que abandonó para ser Director General de Bellas Artes, Archivos y Bibliotecas con Javier Solana como Ministro, una responsabilidad que mantendría hasta 1984.

El impacto ejercido por dicho proyecto supuso un antes y un después en la imagen de la ciudad y en su memoria colectiva. Y todo ello en un momento en que la sensación de pérdida con el cierre de las principales factorías siderúrgicas y navales se apoderaba del sentir ciudadano y evidenciaba la necesidad de sustituir aquel referente industrial por otros configuradores de identidad y prestigio. Las campañas arqueológicas contribuyeron a componer el nuevo paisaje del núcleo originario de la ciudad, a recuperar una parte de su historia al sacar a la luz el recinto de las murallas romanas (siglos III y IV d. C.) y descubrir la importancia de unas termas públicas (siglos I y II d. C.) que, a pesar de tener una existencia conocida, permanecían excavadas parcialmente (Alvargonzález, 1965), así como a aportar nuevos referentes simbólicos en los que fijar el pasado y asentar la memoria. Además, al prolongarse durante casi dos décadas, los trabajos arqueológicos se desarrollaron parcialmente de forma paralela a los de la regeneración urbanística de Cimadevilla, que tuvo que subordinarse a ellos. Esta temprana alianza de intervención urbanística y proyecto cultural en el emplazamiento originario de la ciudad supuso un cambio de usos en el barrio y actuó como reclamo para multiplicar las visitas potenciándolo a todos los niveles.

La sensibilización hacia el patrimonio se ponía de manifiesto nuevamente en las sucesivas intervenciones que, a finales de los años ochenta y a lo largo de los noventa, rehabilitaron los edificios históricos del barrio de Cimadevilla y su entorno más próximo, ya que, como centro histórico de la ciudad, acumulaba numerosas muestras palaciales de 
la Edad Moderna. Al amparo del marco legislativo en materia patrimonial, impulsado por el citado Director General de Bellas Artes Manuel Fernández Miranda en 1982 y regulado por la ley de Patrimonio de 1985 (Rubio, 2003: 79 y 323), se llevó a cabo la restauración de palacios en desuso para asumir nuevas funciones museísticas y culturales, dando respuesta a la doble intención de proteger el patrimonio y aumentar la oferta cultural. En ese contexto, tuvieron su origen el Museo Barjola, inaugurado en 1988 en el palacio barroco de los Jove Huergo y su capilla de la Trinidad, emplazados junto al puerto histórico y al barrio de Cimadevilla, y el Centro Internacional de Arte Palacio de Revillagigedo (Fig. 1), ubicado frente al Muelle gijonés, que entró en funcionamiento en 1991 tras rehabilitar el palacio de Revillagigedo o del Marqués de San Esteban del Mar y su colegiata de San Juan Bautista, una casa fuerte de origen tardomedieval ampliada y monumentalizada en el siglo XVIII (BIC en 1974). La gestión de este último corría a cargo de la Caja de Ahorros de Asturias y se ponía en marcha con la aspiración de convertirse en el gran centro de arte contemporáneo del norte de España. Poco más tarde, la oferta museística se ampliaba con la inauguración en 1995 del Museo de las Termas Romanas de Campo Valdés, que ponía en valor y difundía los hallazgos de las excavaciones desarrolladas entre 1990 y 1994 (García y Fernández, 2003). Los nuevos centros se sumaban al Museo Casa Natal de Jovellanos, en funcionamiento desde 1971, principal museo de la ciudad que albergaba la colección municipal e igualmente ubicado en el barrio en un palacio construido entre los s. XIV-XVI e intervenido varias veces a lo largo de la historia (BIC en 1974). Estas intervenciones ya por sí mismas convertían el barrio de Cimadevilla en referente cultural del Gijón postindustrial, y además esbozaban una actual y renovada imagen sedimentada en la cultura.

La oferta cultural ofrecida desde este núcleo originario de Gijón pretendía dirigirse a un público amplio y con intereses diversos. Junto a la colección de arte asturiano

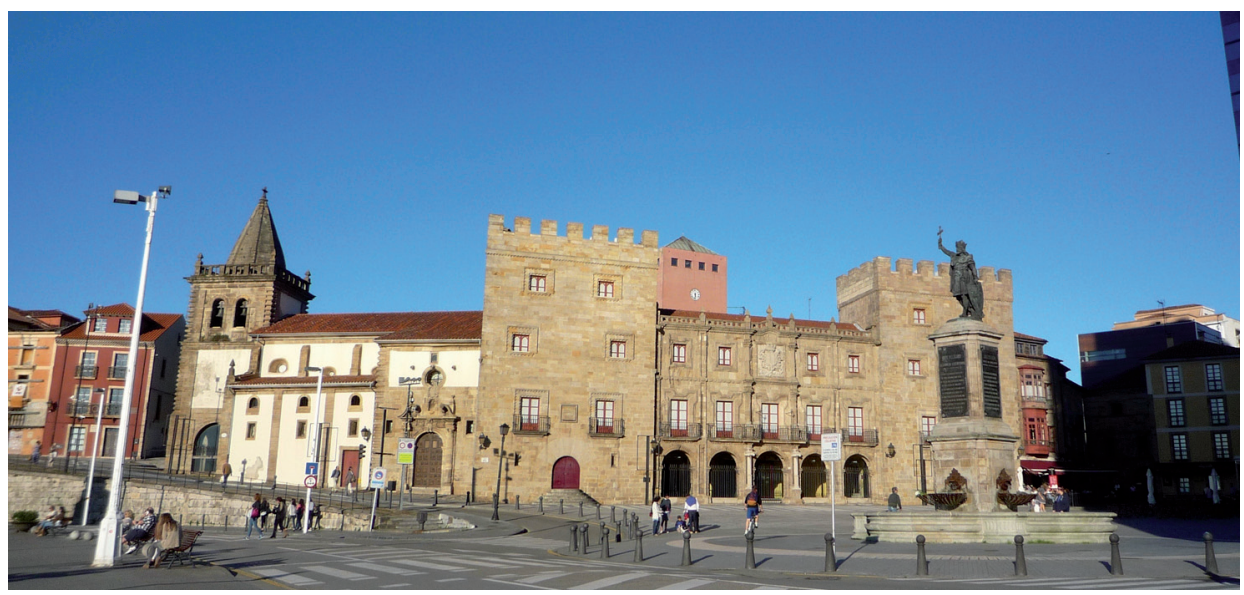

Figura1. Cimadevilla: Centro Internacional de Arte Palacio de Revillagigedo, Colegiata de San Juan Bautista y Torre del Reloj. Fuente: S. Álvarez. 
del Museo Jovellanos y a las propuestas artísticas del momento, que se mostraban en el Centro Revillagigedo, en la Capilla del Museo Barjola se ofertaban exposiciones temporales dedicadas preferentemente a la escultura de vanguardia española, que complementaban la muestra monográfica de la obra pictórica de Juan Barjola instalada de forma permanente en los espacios del palacio tras su donación a la ciudad por la familia del artista. Pero además se podía realizar un itinerario por el caserío popular restaurado, por el rico patrimonio monumental civil y religioso, por las murallas romanas, reconstruidas en una intervención efectista y un tanto discutible, lo mismo que la Torre del Reloj (Fig. 2), y por las baterías e instalaciones militares musealizadas del Cerro de Santa Catalina; se podía asistir a espectáculos en el nuevo teatro descubierto del Cerro, hacer deporte en los espacios e instalaciones habilitadas para ello o contemplar el mar desde una obra que se convertiría rápidamente en símbolo del Gijón renovado, la escultura Elogio del Horizonte de Eduardo Chillida, instalada en la culminación del Cerro de Santa Catalina en 1990 (Fig. 3); cuatro años más tarde se sumaría otra obra escultórica, Nordeste (1994),

Figura 2. Cimadevilla: Murallas romanas y Torre del Reloj. Fuente: S. Álvarez.

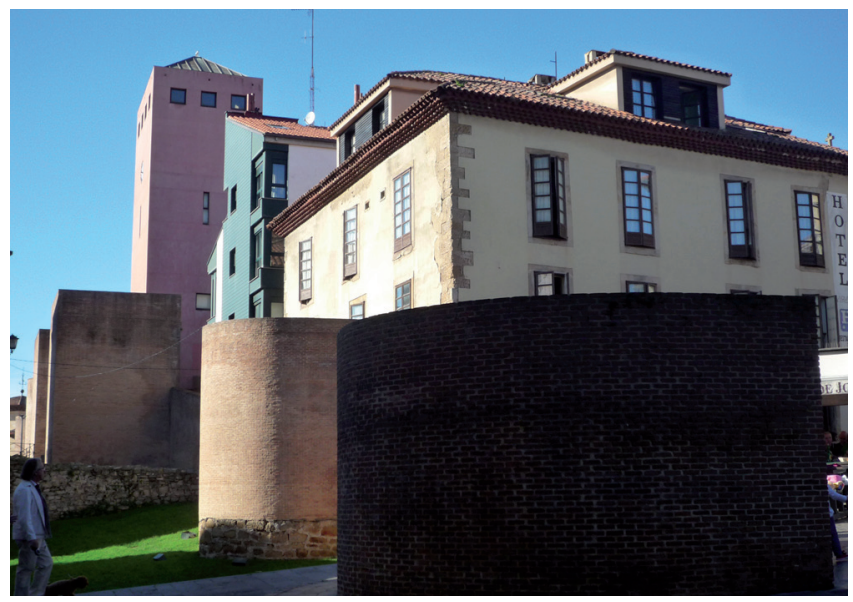

Figura 3. Cerro de Santa Catalina: instalaciones defensivas del Fuerte Viejo (s. XVIII y ss) y Elogio del Horizonte. Eduardo Chillida, 1990. Fuente: S. Álvarez.

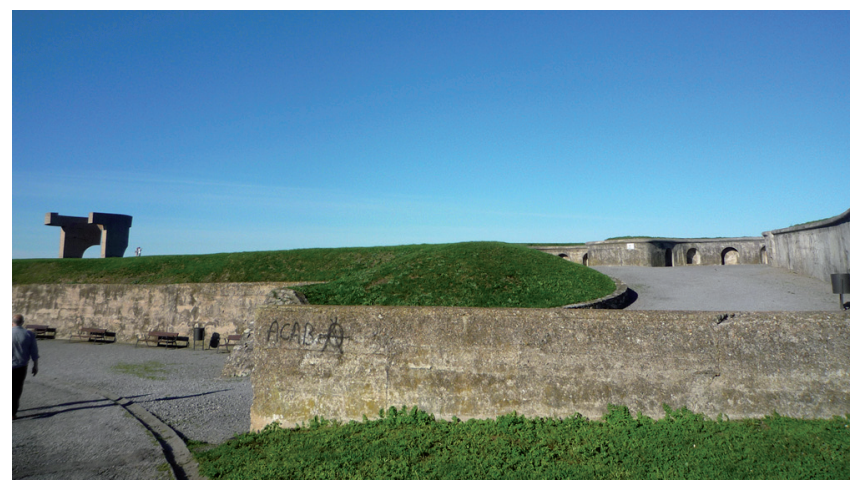


de Joaquín Vaquero Palacios, en el flanco occidental del tómbolo.

De lo expuesto hasta el momento, se deduce que las primeras dotaciones en materia cultural realizadas en Gijón en los años ochenta y comienzos de los noventa afectaron en cuanto a localización al casco histórico de la ciudad, un enclave simbólico por emplazamiento, historia y tradiciones (Álvarez, 2016: 89) y al que se dedicaron también los primeros proyectos de regeneración urbanística, en parte desarrollados paralelamente a la puesta en marcha de los equipamientos culturales comentados. Aunque en aquella etapa los objetivos perseguidos hayan sido fundamentalmente socializadores y pretendiesen acercar la cultura a toda la ciudadanía, no cabe duda de que al estar ubicados en el primer sector urbano sometido a una regeneración integral, que mutaría de la condición de barrio degradado, popular y marinero a lugar representativo del Gijón postindustrial, cultural y turístico, las capacidades como gancho de atracción de visitantes comienzan a ser perceptibles ya entonces en los nuevos equipamientos culturales.

\section{La democratización cultural para toda la ciudad}

El diseño y mantenimiento de una política cultural socializadora supuso que a los equipamientos comentados se sumase otro, también pionero, de enfoque socializador y localizado en el centro urbano. Partiendo de la experiencia de los ateneos obreros, en diciembre de 1981 se inauguraba la Universidad Popular. Esta entidad cultural constituyó el germen de la Fundación Municipal de Cultura y Universidad Popular, cuyos estatutos serían aprobados en febrero de 1993, que se encargaría desde entonces de organizar toda la actividad cultural de carácter municipal y que ha mantenido con enorme éxito una intensa actividad hasta hoy. La Universidad Popular de Gijón es quizá el ejemplo más evidente y temprano de la democratización cultural que fundamentaría las políticas culturales promovidas desde el Ministerio de Cultura en los años ochenta (Rubio, 2003: 39-40), asumidas en Asturias tras la entrada en vigor del Estatuto de Autonomía en 1982, a las que incluso se anticipó.

Los mismos objetivos de socializar la cultura están en el punto de partida de otras dos intervenciones llevadas a cabo en la misma época en el centro urbano. La primera fue la rehabilitación del antiguo Asilo Pola, fundado a comienzos del siglo XX como colegio de hijos de obreros y diseñado por el arquitecto Luis Bellido, que se inaugura en 1991 como Museo Nicanor Piñole para acoger la colección de dicho pintor gijonés, donada a la ciudad por su viuda. La segunda fue la intervención del Teatro Jovellanos, en origen Teatro Dindurra, un edificio diseñado por el arquitecto Mariano Marín e inaugurado en 1899, que había suspendido su actividad en 1987 a causa de su deterioro estructural. El edificio fue restaurado entre 1993 y 1995 al amparo del Plan Nacional de Rehabilitación de Teatros de 1985 (Rubio, 2003: 90-92) según un proyecto de los arquitectos asturianos Fernando Nanclares y Juan González Morillón que estuvo orientado a restablecer el "estado primitivo del teatro clásico". 


\section{LA CULTURA COMO MOTOR DE REVITALIZACIÓN EN UNA INTERVEN- CIÓN URBANÍSTICA INTEGRAL}

El plan diseñado para la ciudad, auspiciado por la permanencia en el gobierno municipal durante varias legislaturas de aquellos que lo promovieron, permitió que la intervención se extendiese más allá de los espacios icónicos señalados hasta estas líneas. Es más, el apoyo a la cultura como recurso de revitalización económica, lo mismo que en otras ciudades industriales sometidas a procesos de reconversión (Álvarez, 2009), se materializó con el diseño de grandes planes estratégicos de regeneración y con el desarrollo de las intervenciones urbanísticas en el resto de la ciudad (Morales, 2010). Estas operaciones se ejecutaron fundamentalmente en los años 90 con el objetivo de sanear los terrenos contaminados por las industrias, de subsanar las cicatrices generadas en la trama urbana por el cierre y derribo de las factorías y de paliar la crisis social, identitaria y económica con proyectos de futuro motivadores para la ciudadanía.

\section{Los nuevos equipamientos del puerto histórico y el sector industrial occidental}

Entre las primeras operaciones debemos señalar la regeneración del waterfront gijonés, que se iniciaba con la intervención del viejo puerto entre 1986 y 1991 para convertirlo en puerto deportivo, según el Plan Especial del Puerto Local (García, 2007). El proyecto, diseñado por los arquitectos Fernando Nanclares y Nieves Ruiz (Nanclares, Ruiz, 1989), a pesar del cambio radical de usos, ahora deportivos y de ocio, se planteó con la premisa de conservar los rasgos singulares del antiguo puerto y de preservar su memoria (Fig. 4), en armonía con el espíritu que había regido la redacción del PGOU.

Las actuaciones en el litoral occidental se siguen desarrollando con la aplicación de otros dos planes especiales de reforma interior, el PERI de Poniente, que afecta al solar de los antiguos Astilleros del Cantábrico y Riera, y el del Santa Olaya - El Arbeyal (1989) en el terreno costero más occidental, también de antiguos astilleros y colindante con el puerto industrial de El Musel.

En ellos se sigue apreciando la recuperación de edificios antiguos para desempeñar nuevas funciones, aunque al tratarse mayoritariamente de instalaciones de carácter industrial, se acusa una menor sensibilidad hacia su conservación. Cabe destacar, no obstante, rehabilitaciones reseñables. Es el caso del edificio que había desempeñado las funciones de aduana y lonja del pescado, rehabilitado por la Autoridad Portuaria de Gijón como edificio de servicios múltiples (culturales, deportivas y hosteleras) con la Sala de Exposiciones Antigua Rula a partir del proyecto de los arquitectos redactores del plan del Puerto Local. También es relevante la creación del Museo del Ferrocarril de Asturias en la antigua Estación del Norte (Tielve, 2014: 79), uno de los museos con mayor número de visitantes de Gijón y de Asturias, que se inaugura en 1998 frente a la nueva playa de Poniente, junto a la que también se mantiene uno de los escasos vestigios de la memoria industrial de la zona: la gran chimenea de ladrillo que perteneció a una empresa maderera 
y que dialoga con la nueva zona residencial de Poniente en el solar ocupado anteriormente por empresas auxiliares de la construcción naval.

A las intervenciones en elementos preexistentes, se suman los equipamientos de nueva creación, que van surgiendo a raíz de la regeneración del litoral occidental y de la conexión del mismo con el resto del tejido urbano al eliminar las barreras generadas por las industrias y la línea ferroviaria. En las nuevas propuestas se aprecia un cambio en el enfoque funcional al realizar una oferta más diversificada en lo cultural que alcanza también el deporte y el ocio. En los antiguos muelles de Fomento se crea un centro de talasoterapia (Talasoponiente) junto a instalaciones náuticas y hosteleras (2006), y en el solar de los Astilleros del Cantábrico se construye el Acuario Atlántico (2008), contemplados ambos equipamientos en el Plan de Excelencia Turística para impulsar la recuperación de este sector y de la ciudad en general.

Figura 4. Puerto Deportivo de Gijón. Fuente: S. Álvarez.

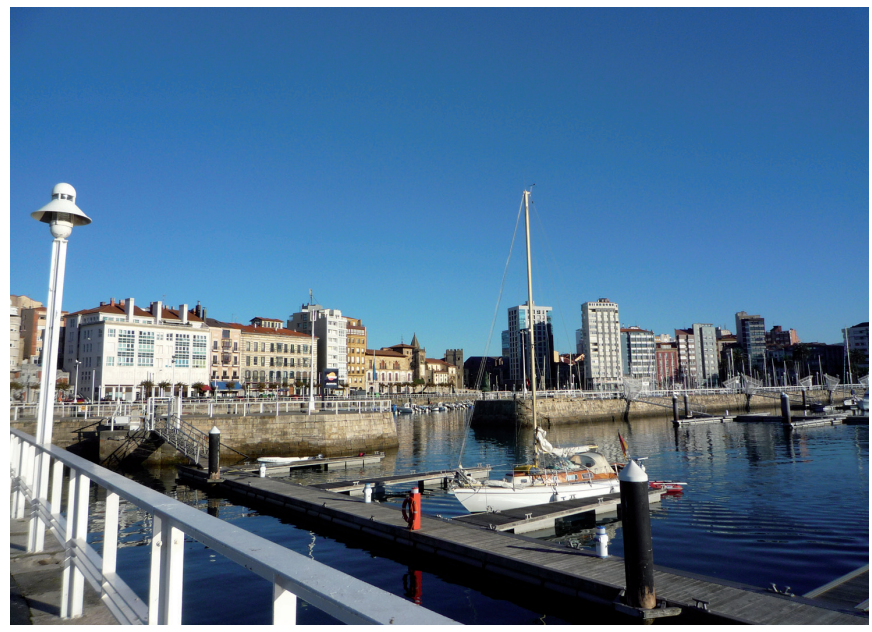

Figura 5. Poniente: Acuario Atlántico. 2008. Fuente: S. Álvarez.

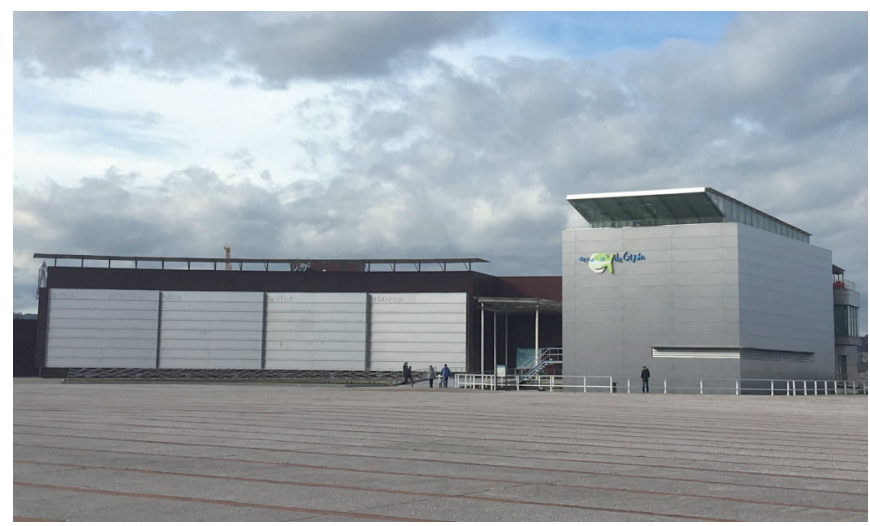


Además, a través de los nuevos parques y playas de este sector urbano se puede apreciar el recurso sistemático a la escultura como aliada del urbanismo en los trabajos de regeneración (Álvarez, 2014 y 2016). El equipamiento escultórico marca un itinerario en el frente marítimo que arranca por el oeste en el Monumento a la Paz Mundial (Manuel Arenas, 1990), instalado en el parque del Lauredal, un espacio otrora privado que ahora contribuye, en el límite oeste de la ciudad, al esponjamiento del densificado barrio obrero del Cerillero. Continúa en la renovada playa del Arbeyal con la escultura Andarín (Miquel Navarro, 1999), a la que se añade en 2005 la obra conmemorativa Homenaje a los Niños de la Guerra (Vicente Moreira), y tiene su tercer enclave artístico en el solar de la antigua fábrica de Moreda, hoy parque público, donde se levanta la Torre de la Memoria (Francisco Fresno, 2000), una pieza evocadora de la memoria industrial del lugar por materia (acero corten), configuración formal y voluntad semántica (Fig. 6). Y fuera ya del programa municipal de equipamiento con esculturas del espacio público, y en este caso con fines conmemorativos para celebrar el centenario de la entrada en funcionamiento del puerto de El Musel, se coloca una nueva escultura en el área de acceso al recinto portuario: Centenario (Pablo Maojo, 2007).

Figura 6. Parque de Moreda: Torre de la Memoria. Francisco Fresno, 2000. Fuente: Francisco Fresno.

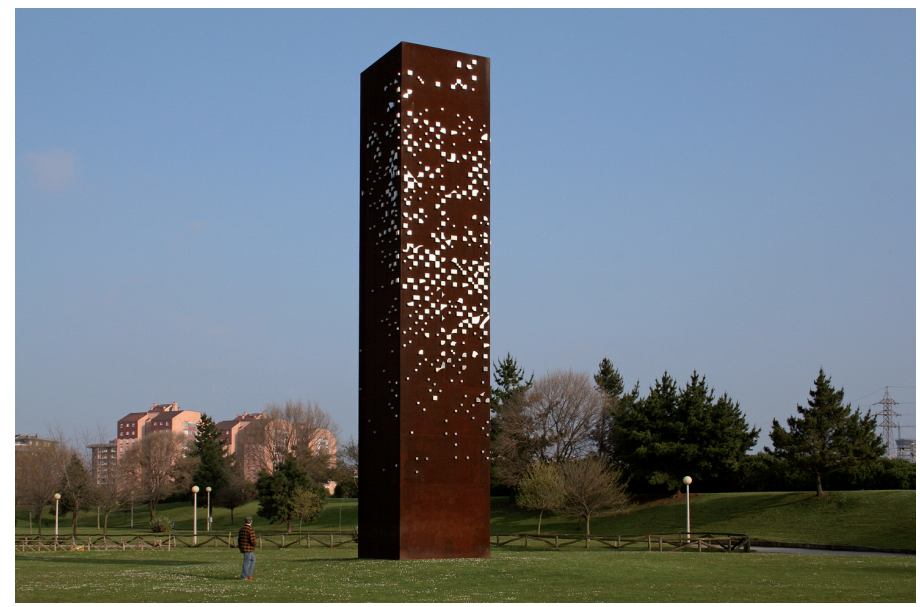

Los equipamientos mencionados persiguen objetivos de diverso tipo. Tratan sin duda de hacer más amable y singular el entorno para su uso por los habitantes del barrio, pero también pretenden atraer a nuevos usuarios y fomentar su revitalización a todos los niveles en una zona obrera que acusaba sobremanera la crisis. Una zona que, no obstante, mantiene la tradición cultural en tanto en cuanto tiene un centro cultural propio, como el resto de los sectores urbanos, el Centro Municipal Integrado Ateneo de La Calzada, inaugurado como tal en 2007, pero de largo funcionamiento como Ateneo Obrero de La Calzada desde los inicios del s. XX. 


\section{Las propuestas y ejecuciones en el centro urbano}

Las intervenciones urbanísticas en el centro urbano tuvieron menor calado que en los barrios industriales del frente litoral, como es lógico, al estar menos afectadas por la reconversión industrial, y se centraron fundamentalmente en la renovación de las principales plazas. Los centros de cultura de esta zona (museos, teatro, Fundación Municipal de Cultura) ya han sido citados anteriormente. Queda no obstante por mencionar la entidad que concentra la mayor actividad en el centro de la ciudad: el Centro de Cultura Antiguo Instituto de Gijón. Se trata de un espacio dedicado a la creación, producción, difusión y formación artística y cultural que comparte con la Fundación Municipal de Cultura, Educación y Universidad Popular el edificio del Real Instituto Asturiano fundado por Jovellanos y construido en su primera fase (planta baja) a partir del diseño de Juan de Villanueva entre 1797 y 1807, que se culminaría casi un siglo más tarde (1887-1892) con otros dos pisos a cargo de Ricardo Marcos Bausá. Nuevamente en este caso se asiste al objetivo señalado en edificios del casco histórico de preservar de un monumento simbólico de la ciudad, en este caso rehabilitado con proyecto de los arquitectos Cosme Cuenca y Jorge Hevia en 1992, que se refuerza con nuevos contenidos culturales.

Asimismo, destaca en este sector urbano el equipamiento con esculturas, en un proyecto meditado y bien planificado que se desarrolló entre 1990 y 2008, con el que se pretendía mejorar el medio configurando nuevos paisajes, así como impulsar el uso del mismo a través de itinerarios artísticos que excedían el casco histórico y los barrios regenerados del oeste, y abarcaban el centro y el resto de las áreas urbanas.

Relacionadas con la reordenación de la zona más simbólica y transitada del centro urbano, el paseo y los jardines de Begoña, se instalaban en 1992 junto al teatro Jovellanos, que en aquel momento se encontraba en fase de rehabilitación, las esculturas Géneris y Obelisco del artista gijonés Joaquín Rubio Camín. También la escultura En la memorial na memoria (María Jesús Rodríguez, 2000) marcaba un enclave artístico en la recién renovada plaza de Europa, mientras que Cubo (Alejandro Mieres, 1995) constituía un elemento del proyecto artístico integral diseñado para la plaza del Humedal por el autor de la escultura en colaboración con el pintor Bernardo Sanjurjo.

\section{El sector oriental del litoral}

El protagonismo otorgado en Gijón a la escultura pública como motor de regeneración partía de la instalación en Cimadevilla del Elogio del Horizonte, que supuso el inicio de una política de equipamiento escultórico del espacio público que acompañó a los trabajos urbanísticos de regeneración integral de la ciudad, una política que permitió publicitar la ciudad como un museo al aire libre (Ciudad de las Esculturas). Y algunas de las mejores piezas de ese equipamiento, realizadas por escultores asturianos y españoles con experiencia en arte público, trazan una ruta artística a través varios kilómetros en el sector oriental del litoral gijonés, que se regenera a partir de un convenio firmado en 1993 
por el Ayuntamiento y la Administración del Estado. La secuencia escultórica en esta área oriental se inicia con Sombras de luz (Fernando Alba, 1999), en el paseo marítimo (Fig. 7), seguida por el Monumento a la Madre del Emigrante (Ramón Muriedas), una obra ya instalada con fines conmemorativos en 1970, Solidaridad (Pepe Noja, 1999), Sin título (Herminio, 2001), Cantu de los dies fuxíos (Adolfo Manzano, 2001), Castillo de Salas (Joaquín Rubio Camín, 2003), Paisaje Germinador (Miguel Ángel Lombardía, 1997) y Homenaje a Galileo Galilei XV (Amadeo Gabino, 1997), que jalonan el resto del paseo, la senda peatonal, modelo de la red contemplada por el POLA (Plan Territorial Especial de Ordenación del Litoral de Asturias, 2005), y los dos parques del frente marítimo oriental gijonés.

En la zona oriental de la ciudad, se puede seguir otro itinerario artístico desde de la desembocadura del río Piles hacia el sector periurbano a través de una serie de recintos singulares. Destaca sobremanera la intervención diseñada por Joaquín Vaquero Turcios para la fachada del estadio de fútbol de El Molinón, la escultura del mismo artista emplazada ante el Recinto Ferial Luis Adaro (Germinación, 2006), así como la realizada por Pablo Maojo para el exterior del Palacio de Deportes de la Guía (Escalada,1992) y las ya ubicadas en la zona periurbana de Cabueñes, ante la Universidad Laboral (Árbol de la Ciencia, Juan Zaratiegui, 1989), y de Viesques, delante de la Escuela de la Marina Civil en el Campus Universitario (Homenaje a la Navegación, Vicente Vázquez Canónico, 1989).

Figura 7. Paseo del Rinconín: Sombras de luz. Fernando Alba, 1999. Fuente: S. Álvarez.

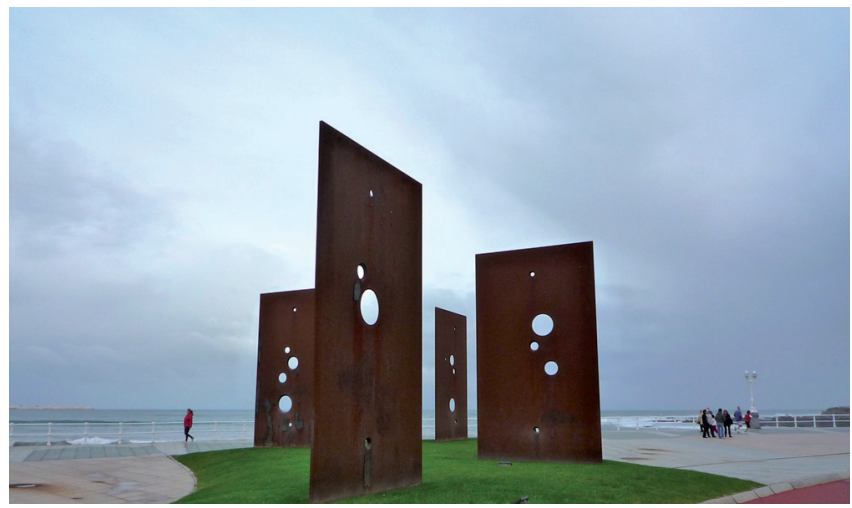

\section{Otros sectores urbanos}

El equipamiento escultórico se expandió también por los barrios de más alta densidad de ocupación en el marco de operaciones de apertura de nuevos espacios, redefiniendo estéticamente el entorno y favoreciendo su uso social. Constituyen ejemplos de esa función regeneradora el Monumento a la República (Acisclo Manzano y Xaime Quesada, 2000), Copulaciones (Pedro Sanjurjo Pieycha, 1998) y Dinámica (Ernesto Knörr, 2004), todas ellas emplazadas en barrios meridionales muy densificados, desarrollados en la segunda 
mitad del siglo XX. En ese mismo entorno, se sitúa la escultura Espacio exterior (Joaquín Rubio Camín, 1990), que había sido concebida inicialmente para el hall de la clausurada Estación Jovellanos. La pieza se trasladó al exterior de la estación de ferrocarril que se construyó provisionalmente e inauguró en 2011 tras ser eliminada la barrera ferroviaria que segregaba el sector litoral occidental del resto de la ciudad, en una intervención previa al desarrollo del Proyecto Ferroviario que quedó sin efecto a causa de la crisis económica.

Asimismo, en barrios y parques de nueva creación, también en el sur, se colocan esculturas introduciendo elementos de singularización, como el Homenaje a las Brigadas Internacionales (Amador Rodríguez, 2001), La Huella (Juanjo Novella, 2002) y Confluencia (Eugenio López, 2001).

En los barrios del sur de Gijón, a las esculturas se fueron sumando otro tipo de equipamientos culturales y nuevamente es en ellos donde queda patente cómo el interés por acercar la cultura a todos los ciudadanos fue una máxima en una ciudad que, tal y como hemos apuntado anteriormente, logró mantener unas políticas culturales socializadoras homogéneas al permanecer ininterrumpidamente el mismo partido político al frente del gobierno municipal durante más de tres décadas (1979-2011). Y el mejor reflejo de ese afán socializador otorgado a la cultura lo ofrecen los equipamientos polivalentes y de proximidad, como los cuatro Centros Municipales Integrados inaugurados en Gijón entre 1998 y 2007, que tratan de dotar de servicios múltiples descentralizados a todos los distritos urbanos. El primero en inaugurarse fue el Centro Municipal Integrado de El Coto (1998), que ocupó el edificio restaurado de la antigua cárcel modernista del mismo nombre. Le siguieron el Centro Municipal Integrado de Pumarín Gijón-Sur (2002) en un interesante edificio de nueva planta proyectado por el arquitecto asturiano José Quidiello (Fig. 8) y, en 2007, el Centro Municipal Integrado de El Llano, además del anteriormente mencionado de La Calzada, antiguo Ateneo ya en funcionamiento, que se sumaba entonces a los centros integrados.

Figura 8. Centro Municipal Integrado de Pumarín Gijón-Sur. Fuente: José Quidiello, 2002.

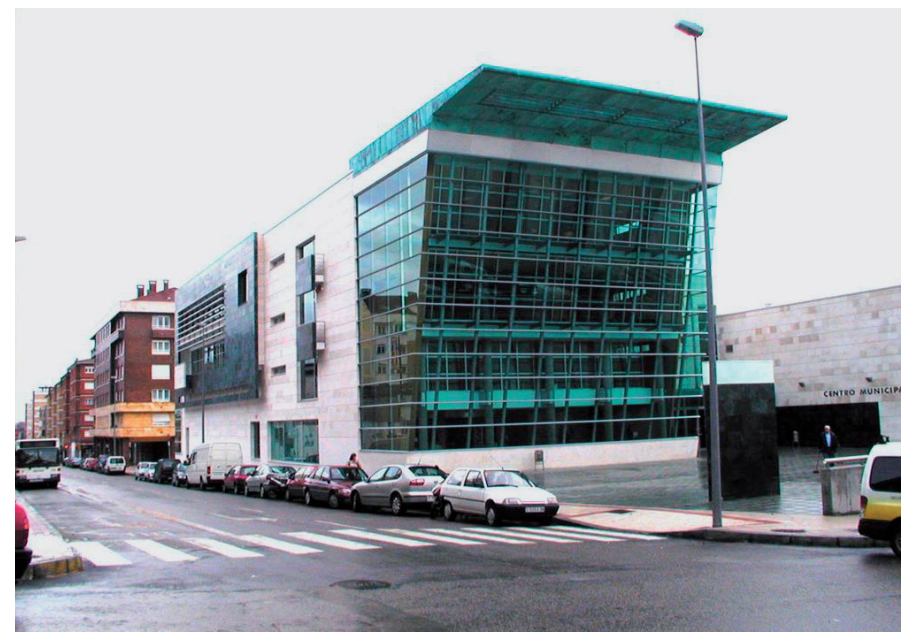




\section{Un equipamiento excepcional en la periferia urbana: Laboral. Centro de arte y creación industrial}

Pero las políticas culturales de Gijón no fueron ajenas a planteamientos orientados al ocio y a la atracción del turismo. Dan cuenta de ello las instalaciones ya mencionadas del Acuario Atlántico y de Talasoponiente (en el sector litoral centro-occidental de Gijón), lo mismo que el Jardín Botánico Atlántico, inaugurado en 2003 en la franja periurbana polifuncional del este de la ciudad, que se contemplaba, como aquellas, en los planes de excelencia turística, y constituía el primer jardín botánico español dedicado en las especies propias del dominio oceánico. Dentro de su recinto encontraron su lugar dos esculturas que habían sido seleccionadas en 2001 para el parque urbano de Los Pericones, Viomvo (Fernando Sinaga) y Érase una vez un árbol (Carmen Cantón), con lo que el equipamiento escultórico se expande también por los recintos de nueva creación promovidos con intenciones turísticas.

No obstante, el ejemplo más evidente de ese planteamiento lo ofrece Laboral Centro de Arte y Creación Industrial que se inaugura en 2007 y es uno de los primeros centros españoles dedicados a la creación junto a Matadero Madrid. Centro de Creación Contemporánea y Tabakalera. Centro Internacional de Cultura Contemporánea de San Sebastián (Fernández, 2010: 144, 172, 228). Laboral, con un planteamiento pionero en España como laboratorio de industrias creativas centrado en la producción y exposición de arte tecnológico, trataba de dar respuesta a la intención de incorporar la ciudad en los circuitos culturales internacionales, en un momento en que comenzaban a generalizarse los planes estratégicos de cultura y se planificaba la cultura territorial con una distribución equilibrada y optimizada de los equipamientos (Álamo, 2014: 5). Como contenedor del centro, en lugar de optar por la obra espectacular de un arquitecto estrella, según la práctica generalizada, se eligieron los talleres del edificio histórico de la Universidad Laboral,

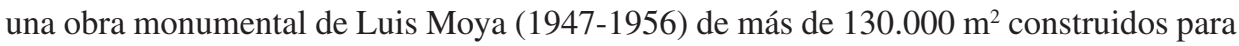
el que, en el año 2000, el Gobierno del Principado comenzó a contemplar el diseño de un Plan Estratégico. Tras una cuidada y respetuosa rehabilitación iniciada en 2001 por el equipo de arquitectos dirigido por Xerardo Estévez, la antigua Universidad Laboral se puso en marcha como Laboral Ciudad de la Cultura (Fig. 9), un enorme espacio musealizado y con programación de visitas, dotado de funciones educativas (dependencias universitarias, centro de bachillerato, de formación profesional de arte dramático y danza y de Música), de investigación (centro de I+D+i ), de comunicación (sede de la Radiotelevisión del Principado), dedicadas a espectáculos e industrias culturales en el Teatro Laboral, que se inaugura como el centro de arte en 2007, además de las deportivas, hosteleras y las creativas del centro de arte.

Laboral Centro de Arte y Creación Industrial (Fig. 10) tuvo sus orígenes como “fundación privada-pública" (Fernández León, 2010: 148) que gestionaba las instalaciones de unas inmensas naves más de $14.000 \mathrm{~m}^{2}$, en las que la actividad se centraba tanto en la producción y coproducción, como en la exposición y difusión de propuestas artísticas diversas relacionadas con el mundo tecnológico. 
Esta intervención, de alto impacto en su conjunto tanto por el edificio que alberga sus actividades como por las propuestas a ejecutar, ha sido uno de los mayores empeños de los gobiernos municipal y autonómico del Principado. De modo que, potenciando el interés arquitectónico y patrimonial del edificio (desemantizado de las connotaciones franquistas) y los nuevos usos del mismo, y muy en especial Laboral Centro de Arte y Creación Industrial, pretendía dinamizar culturalmente la ciudad y la región y contribuir a su revitalización proyectándola a nivel nacional e internacional.

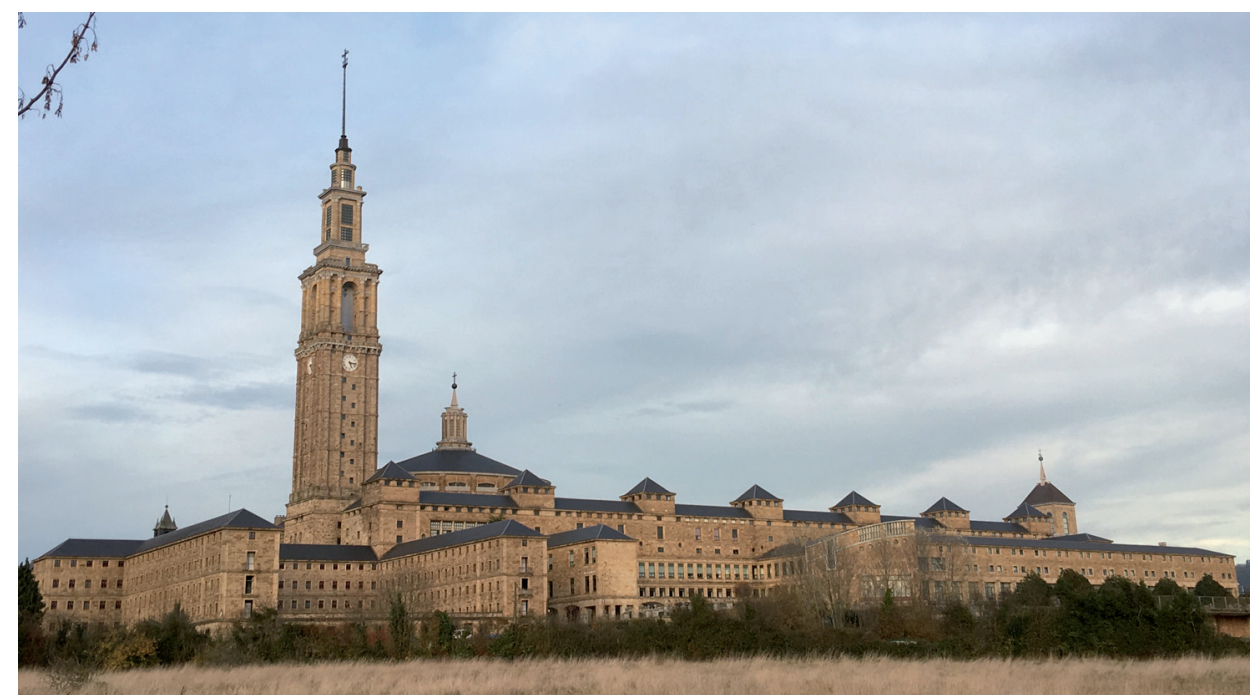

Figura 9. Laboral Ciudad de la Cultura. Fuente: S. Álvarez.

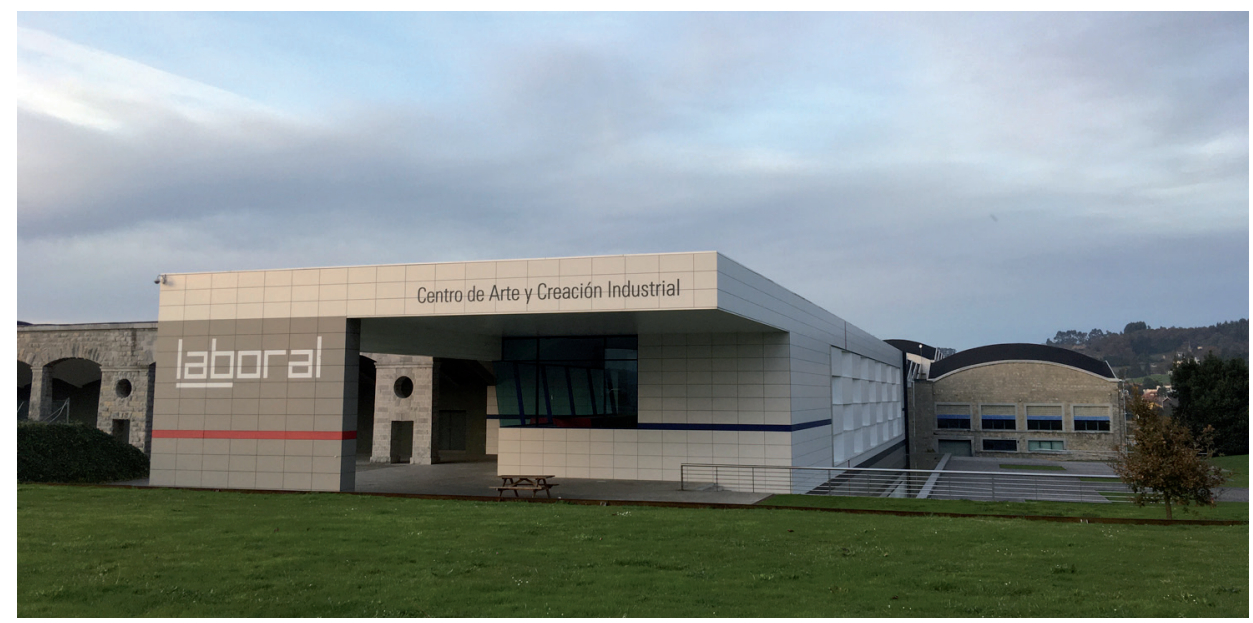

Figura 10. Laboral Centro de Arte y Creación Industrial. 2007. Fuente: S. Álvarez. 
Y en relación con ello, Laboral, junto con el Elogio del Horizonte, fueron concebidos por la administración como algo más que elementos de un nuevo equipamiento cultural al otorgarles funciones simbólicas y promover su imagen como iconos representativos de la modernización con los que pasaría a identificarse también la comunidad autónoma. Así, Gijón pasó a desempeñar un papel representativo como ciudad renovada culturalmente y con una capacidad de atracción en Asturias similar a la que Bilbao detenta en el País Vasco. De este modo, ambas, Bilbao y Gijón, en el contexto histórico al que nos referimos, pasaron a ser los polos culturales del litoral cantábrico y miembros del arco cultural atlántico

\section{FUNCIONAMIENTO Y DERIVA DE LA CULTURA EN LA GRAN RECESIÓN}

El impulso pionero a la cultura con fines socializadores y regeneradores experimentó un cambio radical con el inicio de la gran recesión de 2008, en un momento en que podrían comenzar a recogerse resultados significativos de los equipamientos ya existentes. Por una parte se asiste a la interrupción de nuevos proyectos culturales, como el que se había planteado para acoger el Museo de Gijón en la antigua Fábrica de Tabacos, que se había clausurado el año 2002 tras un funcionamiento de más de un siglo y medio en el edificio barroco (s. XVII-XVIII) del desamortizado Convento de las Agustinas Recoletas del barrio de Cimadevilla. Aun así, se instalaron todavía algunas esculturas públicas fuera del Proyecto Arte Público en Gijón, de las que destaca Hacia la luz (Francisco Fresno, 2009) como pieza más relevante, tanto por sí misma como por su capacidad para dialogar con el entorno. Por otra parte, se aprecia el letargo funcional de algunos de los centros creados en las décadas anteriores, casi siempre por falta de presupuesto con el que abordar programaciones de interés, pues todos ellos son centros de titularidad pública y visita gratuita. El caso más notorio lo ofrece el Museo Barjola, dependiente del Gobierno del Principado de Asturias, que vio recortadas las interesantes exposiciones temporales que en él se celebraban. Pero los recortes afectaron también a la programación y al impulso que habían tomado el resto de los centros museísticos y culturales, sumándose a ellos el desinterés por la apuesta cultural que pronto mostraron algunas entidades encargadas de su gestión, como ocurrió en el Centro Cultural Palacio de Revillagigedo cuando la Caja de Ahorros de Asturias abandona sus políticas culturales para centrarse estrictamente en las financieras.

Más notorio y doloroso por las expectativas que se le otorgaron inicialmente, es el funcionamiento actual de Laboral. Centro de Arte y Creación Industrial, un centro que arrancó con una programación brillante y de alcance internacional, dentro de su especialización, con el respaldo de una elevada financiación mixta, pública y privada, y que actualmente se muestra incapaz de mantenerse con el presupuesto adaptado a la situación económica, exclusivamente público y notablemente mermado. No obstante, esta situación no se debe solamente a los recortes económicos sufridos, sino también al carácter mino- 
ritario y exclusivo con el que se concibió, siendo las actividades del espacio de creación muy reconocidas internacionalmente pero ajenas a la realidad social y cultural de la ciudad y la región.

Con todo, en términos generales, es preciso reconocer los beneficios aportados a la ciudad por los equipamientos culturales, que han contribuido a la terciarización y diversificación funcional al incorporar nuevas actividades e industrias culturales que, a su vez, han incidido en el impulso económico. El aumento de la participación ciudadana en el consumo de la cultura junto con el incremento del turismo cultural y deportivo fue notorio a partir de 1990, coincidiendo con la regeneración del barrio de Cimadevilla, la transformación del puerto local en instalación deportiva y recreativa, y la inauguración del Elogio del Horizonte. Y siguió en aumento al socaire de la creación de las nuevas instalaciones contempladas en los planes de excelencia turística. Por otra parte, son incuestionables las aportaciones que los equipamientos culturales han realizado a la regeneración urbanística (ampliación del espacio público y mejora de la trama urbana), social y cultural (democratización de la cultura y aproximación arte-vida). Es preciso valorar también las consecuencias positivas en cuanto a la conservación del patrimonio preexistente y a la creación de nuevos patrimonios y, en relación con ello, en cuanto al cambio de imagen de la ciudad, que ha visto sustituido su paisaje desindustrializado por otro renovado en lo visual y en lo conceptual y simbólico. 


\section{BIBLIOGRAFÍA}

Álamo, E. del, «Los espacios de la cultura», in Manual Atalaya Apoyo a la Gestión Cultural, 2014. [http://atalayagestioncultural.es/capitulo/espacios-cultura] (consulta 29-5-2018).

Álvarez Martínez, M. S., «Problemáticas de la ciudad industrial: la imagen perdida, las nuevas funciones y la creación de patrimonios», in J. Parrado del Olmo y F. Gutiérrez Baños (coords.), Estudios de Historia del Arte. Homenaje al Profesor De la Plaza Santiago. Universidad de Valladolid, Valladolid, 2009, pp. 301-307.

Álvarez Martínez, M. S., «Un nuevo arte para Gijón: compromiso público y usurpación retórica», en M. C. Morales (coord.), El Waterfront de Gijón (1985-2005). Nuevos Patrimonios en el Espacio Público, Oviedo, Eikasia, 2010, pp. 61-107.

Álvarez Martínez, M. S., «El arte como recurso: intervenciones escultóricas y propuestas artísticas en la regeneración de las villas costeras asturianas», in Ábaco. Revista de Cultura y Ciencias Sociales, $2^{a}$ época, vol. 2/3, nº 80/81, 2014, pp. 41-47.

Álvarez Martínez, M. S., «Nuevos patrimonios frente al Cantábrico: las intervenciones artísticas en los núcleos costeros de Asturias», in M.S. Álvarez Martínez (coord..), Espacios portuarios y villas costeras. Modelos de estrategias urbanísticas y patrimoniales de regeneración y transformación del litoral asturiano, Eikasia, Oviedo, 2014, pp. 8-16.

Álvarez Martínez, M. S., «La patrimonialisation de la sculpture publique: l'exemple des villes portuaires asturiennes (nord-ouest de l'Espagne)», in J. R. Morice, G. Saupin y N. Vivier (Drs.), Mutations de la culture patrimoniale, Collections «Des Socieétés», PUR Presses Universitaires de Rennes, Rennes, 2015, pp. 225-244.

Álvarez Martínez, M. S., «La evolución del núcleo originario de Gijón. Cimadevilla: presencia simbólica, realidad patrimonial y usos turísticos», in M. A. Chaves Martín (Ed.), Ciudad, Arquitectura y Patrimonio, Grupo de Investigación Arte, Arquitectura y Comunicación en la Ciudad Contemporánea. Universidad Complutense de Madrid, Madrid, 2016, pp. 89-99.

Alvargonzález, C., Termas romanas de Campo Valdés-Gijón. Monografía por don Calixto Alvargonzález con la colaboración de don Julio Somoza y don Juan Alvargonzález, Editorial Joaquín Bonet, Gijón, 1965.

Alvargonzález Rodríguez, R. M., Industria y espacio portuario en Gijón, Junta del Puerto de Gijón, vol. I, Gijón, 1985, pp. 7-173.

Bauman, Z., La cultura en el mundo de la modernidad líquida, Fondo de Cultura Económica, Ciudad de México, 2013.

Benito del Pozo, P., «Discursos, propuestas y acciones sobre la ciudad postindustrial», in Anales de Geografía, no 24, 2004, pp. 9-29.

Bianchini, F y Parkinson, M. (eds.), Cultural policy and urban regeneration, Manchester University Press, 1993.

Colantonio, A. y Dixon, T., Urban Regeneration \& Social Sustainability, Best practice from European cities, John Wiley \& Sons, 2011. 
Dambron, P., Patrimoine industriel et développement local, Éditions Jean Delaville, París, 2004

Díez Faixat, V., Gijón. El espacio y el aire: arquitectura gijonesa, nº 6, GEA, Gijón, 2000, pp. 106-108 y 112.

Fernández Cuesta, G., Fernández Prieto, J. R. y Sevilla Álvarez, J., «Los espacios industriales promovidos», in G. Fernández Cuesta y F. Quirós Linares (eds.), Atlas Temático de España, vol. 4, Ediciones Nobel, Oviedo, 2010, pp. 216-259.

Fernández García, A., «Efectos paisajísticos de la reconversión en las ciudades asturianas de tradición industrial», in Actas del Congreso de la Asociación de Geógrafos de España (AGE), Valencia, 1991, pp. 471-477.

Fernández Gutiérrez, M. F. y Álvarez Espinedo, R., «La obra pública municipal en Gijón entre 1979 y 2006» en VV. AA., La obra pública municipal en Gijón (1782-2006), Ayuntamiento de Gijón, Gijón, 2006.

Fernández León, J., Nuevos centros culturales para el siglo XXI en España. Consenso y conflicto, EECID, 2010.

Fernández Miranda, M., Los orígenes de Gijón, Ayuntamiento de Gijón, Gijón, 1989.

Fernández Ochoa, C., «Historia del Proyecto Gijón de Arqueología», in Complutum, n 6,1, pp. 29-37.

García Díaz, P. y Fernández Ochoa, C., «Las termas romanas de Campo Valdés (Gijón): presentación didáctica y actualización tecnológica», in II Congreso Internacional sobre musealización de yacimientos arqueológicos: nuevos conceptos y estrategias de gestión y comunicación, 2003, pp. 270-274.

García Quirós, R. M., «Un nuevo espacio para Gijón: la transformación del viejo puerto», in Liño. Revista Anual de Historia del Arte, n 13, pp. 105-122.

Lorente Lorente, J. P., «Museos y regeneración urbana: del desarrollismo al crecimiento sostenible», Mus-A: Revista de los museos de Andalucía, no 4, 2004.

Madrid, V. de la, «Muséographie dans des édifces historiques. Le projet de Gijón», in J-R. Morice, G. Saupin y N. Vivier (eds.), Mutations de la culture patrimoniale, Presses Universitaires de Rennes, Rennes, 2015, pp. 245-259.

Martí Font, J. M., "La cultura... ¿salvavidas de Europa?”, El País, Madrid, 10 septiembre 2011, https://elpais.com/diario/2011/09/10/cultura/1315605601_850215.html (26/06/2018)

Martín Rodríguez, A., Suárez Domínguez, F., Coz Díaz, J. J. del, Lozano Martínez Luengas, A. y Cuartas Suárez, A., «Rehabilitación de los talleres de la Universidad Laboral de Gijón», ReCoPar, Revista Electrónica, n 5, abril-diciembre 2007.

Monográfico de rehabilitación en arquitectura, Technal, $4^{\circ}$ trimestre 2010 [https://www. technal.com/globalassets/upload/archivos-spain/imagenes-spain/profesional/documentacion/perfil/monografico_rehabilacion.pdf] (26/06/2018)

Morales Saro, M. C., «Marca Gijón: la imagen de la ciudad», in Liño. Revista Anual de Historia de Arte, n 13, 2007, pp. 123-135. 
Morales Saro, M. C., (coord.), El waterfront de Gijón (1985-2005). Nuevos patrimonios en el espacio público, Eikasia, Oviedo, 2010.

Nanclares, F. y Ruiz, N., «Plan Especial de Reforma Interior del Puerto Local de Gijón», in Obradoiro. Revista de Arquitectura, n 15, 1989.

Pol, F. y Martín, J. L., «La recuperación del casco histórico de Gijón», Geometría, nº 8, 1989, pp. 16-31.

Remesar, A., Public Art and Urban Regeneration. Monografies Socio-ambientales, 6, Barcelona, 1997.

Rubio Aróstegui, J. A., La política cultural del Estado en los gobiernos socialistas: 19821996, Ediciones Trea, Gijón, 2003.

Rubio Aróstegui, J. A., «Niveles de discurso de la política cultural y sus interacciones en la construcción de la realidad artística y cultural», in Periférica. Revista para el análisis de la cultura y el territorio, $\mathrm{n}^{\circ}$ 9, 2008, pp. 21- 40.

Sendín García, M. A., «Incidencia de la crisis industrial en el paisaje urbano de Gijón», Ería, 22, 1990, pp. 184-189.

Tielve García, N., «Puerto, espacio litoral y Patrimonio Industrial en el Principado de Asturias», in Álvarez Martínez, M. S. (coord..), op. cit., 2014, pp. 45-84.

Vera Rebollo, J. F. y Dávila Linares, J. M., «Turismo y Patrimonio histórico cultural», in Estudios Turísticos, n 126, 1995, pp. 161-177

VV. AA. La industria cultural. La cultura como factor de desarrollo económico local, III Jornadas Espacios de Creación Contemporánea, Avilés, 2007. 